Supporting Information for:

\title{
Ultrafast Proton Transfer Dynamics of Hydroxystilbene Photoacids
}

Frederick D. Lewis, ${ }^{* \dagger}$ Louise Sinks, ${ }^{\dagger}$ Wilfried Weigel ${ }^{\ddagger}$ and Elizabeth M. Crompton ${ }^{\dagger}$ 
Table S1. ZINDO-Calculated Energy, Wavelength, and Oscillator Strength, and Character of Excited States ${ }^{\mathrm{a}}$

\begin{tabular}{|c|c|c|c|c|c|}
\hline & State & $\begin{array}{l}\Delta \mathrm{E} / \\
\mathrm{kcal}^{\mathrm{b}}\end{array}$ & $\begin{array}{l}\lambda / \\
\mathrm{nm}^{\mathrm{b}}\end{array}$ & $f^{\mathrm{c}}$ & State character ${ }^{\mathrm{d}}$ \\
\hline \multirow[t]{4}{*}{ 33SNOH } & $\mathrm{S}_{1}$ & 92.8 & 308.0 & 1.0599 & $0.95(41-42)$ \\
\hline & $\mathrm{S}_{2}$ & 96.2 & 297.3 & 0.0969 & $0.71(41-43)+0.41(39-42)-0.30(38-43)$ \\
\hline & $\mathrm{S}_{3}$ & 97.5 & 293.3 & 0.0475 & $0.57(40-42)+0.54(41-44)$ \\
\hline & $\mathrm{S}_{4}$ & 116.7 & 244.9 & 0.3160 & $\begin{array}{l}0.46(39-42)-0.49(41-45)-0.44(39-43)-0.39(41- \\
43)\end{array}$ \\
\hline \multirow[t]{4}{*}{ 33SNO- $^{-}$} & $\mathrm{S}_{1}$ & 61.2 & 467.2 & 0.0906 & $-0.72(41-42)-0.57(41-43)+0.35(41-44)$ \\
\hline & $\mathrm{S}_{2}$ & 76.5 & 373.6 & 0.0121 & $-0.72(41-43)+0.65(41-42)$ \\
\hline & $\mathrm{S}_{3}$ & 82.5 & 346.4 & 0.6808 & $-0.87(39-42)-0.31(39-43)$ \\
\hline & $\mathrm{S}_{4}$ & 87.5 & 326.9 & 0.1548 & $0.79(39-43)$ \\
\hline \multirow[t]{4}{*}{ 34SNOH } & $\mathrm{S}_{1}$ & 90.1 & 317.2 & 1.1617 & $-0.97(41-42)$ \\
\hline & $\mathrm{S}_{2}$ & 95.4 & 299.6 & 0.0628 & $-0.30(40-42)+0.72(41-43)$ \\
\hline & $\mathrm{S}_{3}$ & 97.0 & 294.6 & 0.0369 & $-0.77(41-44)-0.32(39-42)$ \\
\hline & $\mathrm{S}_{4}$ & 115.2 & 248.1 & 0.1878 & $-0.46(40-42)-0.36(41-43)+0.64(41-45)$ \\
\hline \multirow[t]{4}{*}{ 34SNO- $^{-}$} & $\mathrm{S}_{1}$ & 59.4 & 481.1 & 1.1723 & $0.83(41-42)+0.46(41-43)$ \\
\hline & $\mathrm{S}_{2}$ & 68.1 & 420.1 & 0.1431 & $-0.83(41-43)+0.44(41-42)$ \\
\hline & $\mathrm{S}_{3}$ & 81.6 & 350.5 & 0.0000 & $-0.43(40-43)-0.40(40-42)+0.46(40-44)+0.40(40-$ \\
\hline & $\mathrm{S}_{4}$ & 88.5 & 323.0 & 0.1069 & $\begin{array}{l}49)+0.32(40-47)+0.31(40-55) \\
0.95(41-46)\end{array}$ \\
\hline \multirow[t]{4}{*}{ 43SNOH } & $\overline{\mathrm{S}_{1}}$ & 90.0 & 317.7 & 1.3491 & $-0.97(41-42)$ \\
\hline & $\mathrm{S}_{2}$ & 97.2 & 294.1 & 0.0096 & $-0.56(41-45)-0.42(40-44)-0.32(39-45)+0.55(40-$ \\
\hline & $\mathrm{S}_{3}$ & 98.3 & 291.0 & 0.0045 & 42) \\
\hline & $\mathrm{S}_{4}$ & 115.6 & 247.3 & 0.0107 & $\begin{array}{l}-0.65(41-43)-0.55(38-42)+0.31(39-43) \\
0.82(41-44)\end{array}$ \\
\hline \multirow[t]{4}{*}{ 43SNO- $^{-}$} & $\mathrm{S}_{1}$ & 58.2 & 491.1 & 0.0930 & $-0.91(41-42)+0.38(41-44)$ \\
\hline & $\mathrm{S}_{2}$ & 78.9 & 362.3 & 1.0236 & $0.94(39-42)$ \\
\hline & $\mathrm{S}_{3}$ & 86.6 & 330.0 & 0.1161 & $-0.61(41-44)-0.33(41-42)+0.42(41-46)+0.39(41-$ \\
\hline & $\mathrm{S}_{4}$ & 87.0 & 328.8 & 0.0004 & $-0.72(40-42)+0.47(40-44)$ \\
\hline \multirow[t]{4}{*}{ 44SNOH } & $\mathrm{S}_{1}$ & 87.3 & 327.7 & 1.3566 & $0.97(41-42)$ \\
\hline & $\mathrm{S}_{2}$ & 97.0 & 294.8 & 0.0298 & $\begin{array}{l}-0.35(39-44)-0.34(40-45)+0.76(41- \\
45)+0.37(39-42)\end{array}$ \\
\hline & $\mathrm{S}_{3}$ & 97.8 & 292.2 & 0.0048 & $0.67(41-43)+0.54(40-43)+0.39(40-43)$ \\
\hline & $\mathrm{S}_{4}$ & 113.3 & 252.4 & 0.0028 & $-0.87(41-44)-0.32(40-42)$ \\
\hline \multirow[t]{4}{*}{ 44SNO $^{-}$} & $\mathrm{S}_{1}$ & 56.5 & 506.2 & 1.4361 & $-0.94(41-42)$ \\
\hline & $\mathrm{S}_{2}$ & 77.1 & 370.8 & 0.0287 & $0.92(41-43)+0.33(39-43)$ \\
\hline & $\mathrm{S}_{3}$ & 80.4 & 355.6 & 0.0000 & $\begin{array}{l}-0.53(40-44)-0.34(40-47)+0.56(40- \\
42)+0.39(40-49)\end{array}$ \\
\hline & $\mathrm{S}_{4}$ & 88.7 & 322.2 & 0.0842 & $-0.91(41-46)$ \\
\hline
\end{tabular}

${ }^{\mathrm{a}}$ Calculations on MM/PM3 geometry. ${ }^{\mathrm{b}}$ ZINDO-calculated energy and wavelength.

${ }^{\mathrm{c}}$ Oscillator strength. ${ }^{\mathrm{d}}$ Only transitions with coefficient constant $\geq 0.3$ were chosen.

$\mathrm{HOMO}=41 ; \mathrm{LUMO}=42$. 


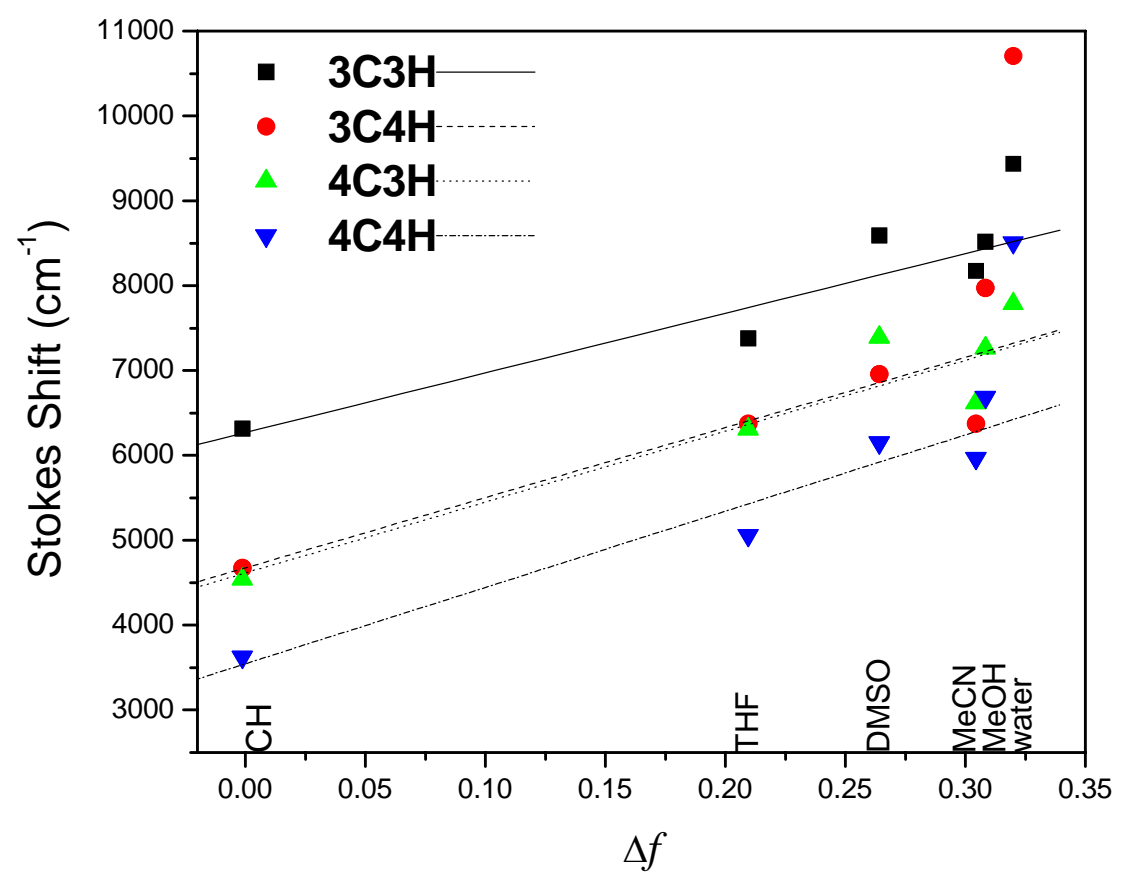

Figure S1. Solvatochromic plot of Stokes shifts for 33SNOH (•), 34SNOH (•), 43SNOH ( $\triangle)$, 44SNOHH $(\nabla)$. The solvent polarity function, $\Delta f$, is calculated according to eq 3-2 for cyclohexane, tetrahydrofuran, dimethyl sulfoxide, acetonitrile, methanol, and water, in order of increasing $\Delta f$. The water points are not included in the fits.

The solvent polarity induced shifts in the absorption and emission maxima can be used to calculate the dipole moments of the Franck-Condon excited state $\left(\mu_{\mathrm{e}}^{\mathrm{FC}}\right)$ and the charge transfer (CT) excited state $\left(\mu_{\mathrm{e}}{ }^{\mathrm{CT}}\right)$, according to eqs $1-3,{ }^{1}$

$$
\begin{gathered}
\Delta f=(\varepsilon-1) /(2 \varepsilon+1)-\left(n^{2}-1\right) /\left(2 n^{2}+1\right) \\
v_{\text {abs }}=-1 /\left(4 \pi \varepsilon_{0}\right)\left\{2 /\left(h c a^{3}\right)\right\} \mu_{\mathrm{g}}\left(\mu_{\mathrm{e}}^{\mathrm{FC}}-\mu_{\mathrm{g}}\right) \Delta f+\text { const. } \\
v_{\text {flu }}=-1 /\left(4 \pi \varepsilon_{0}\right)\left\{2 /\left(h c a^{3}\right)\right\} \mu_{\mathrm{e}}^{\mathrm{CT}}\left(\mu_{\mathrm{e}}^{\mathrm{CT}}-\mu_{\mathrm{g}}^{\mathrm{FC}}\right) \Delta f+\text { const.' }
\end{gathered}
$$

where $v_{\text {abs }}$ and $v_{\text {flu }}$ are the absorption and fluorescence maxima, $\varepsilon_{0}$ is the permittivity of free space, $a$ is the solvent cavity radius in $\AA$ (here $a=6 \AA$ ), $\varepsilon$ is the solvent dielectric constant, $n$ is the solvent refractive index, and $\mu_{\mathrm{g}}{ }^{\mathrm{FC}}$ is assumed to be equal to $\mu_{\mathrm{g}}$. The ground state dipole moments were calculated in CAChe \{Goerner, 1995 \#91;Goerner, 1995 \#91\} using the PM3 geometry. To calculate the dipole moments of the FC and CT states, the absorption and emission maxima were plotted against the solvent polarity function in a Lippert-Mataga plot (Figure S1). The absorption and emission maxima in 
DMSO fall well below the line formed by the other solvents, plausibly an effect of the hydrogen bonding in DMSO. The excited state dipole moments were calculated from the slopes of the Lippert-Mataga plots of absorption and emission maxima, excluding the water and DMSO data, and are listed in Table 2.

\section{References}

(1) (a) Lippert, E. Z. Naturforsch. 1955, 10a, 541-545. (b) Liptay, W. Z. Naturforsch. 1965, 20a, 1441-1471.

(2) CAChe, 4.4; Fujitsu Limited: Chiba, Japan.

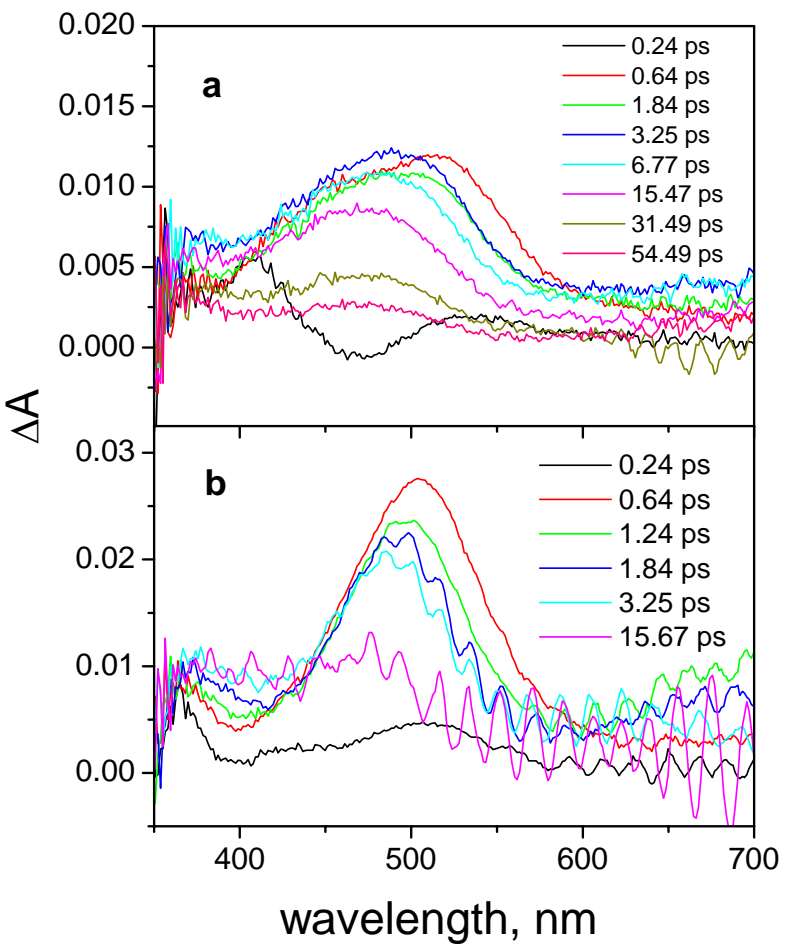

Figure S2. Transient absorption spectra for $33 \mathrm{SNOH}$ and $34 \mathrm{SNOH}$ in MW solution. 